\title{
Outgoing call quality evaluation of GSM network services in Epe, Lagos State
}

\author{
${ }^{1,2}$ Shoewu, O. and ${ }^{2}$ Edeko, F.O. \\ ${ }^{1}$ Department of Electronic and Computer Engineering, Lagos State University, \\ Epe Campus \\ ${ }^{2}$ Department of Electrical and Electronics Engineering, University of Benin, Edo State
}

\begin{abstract}
This study is aimed at presenting a report on the quality of service of network optimization and evaluation of key performance indices provided by GSM operators. This is expressed in terms of the ability to establish and maintain call connections, call retention, handover, inter and intra network call set-up. Test points within the service areas were randomly selected and in each of these locations, series of measurements were taken. Conclusively, a model of service quality and a set of dimensions for comparative evaluation, which could provide useful directions to regulators and service providers, are presented. Also, we shall briefly analyse the outgoing call quality to suit this purpose.
\end{abstract}

Keywords: GSM, Teledensity, Telecommunications, Service Quality, Call Drop Rate

\section{INTRODUCTION}

When Nigeria gained her independence in 1960, there were only 18,724 functional telephone lines for an estimated population of 45 million, which was a "teledensity" ratio of 0.04 telephones per 100 people. (Shoewu et al., 2008). During the thirty-odd years of military rule, there was very little by way of investment in telecommunications, and other sectors did not fare any better. According to the International Telecommunication Union, by 1996 Nigeria's teledensity ratio was a mere 0.36 .It rose slightly to 0.4 by 1999; according to the Nigeria Communication Commission (NCC). Nigeria's teledensity is a far cry from the African average of 1.67. Even the NCC admits that Nigeria has had a very limited telephone network for many years, and the waiting list is estimated at over 10 million people, who have applied to the incumbent monopoly, NITEL (established in 1985) for services. However, with the liberalization of the telecommunication industry in 2001, the story changed dramatically. The teledensity ratio had tripled within just one year of GSM operation. By May 2005 Nigeria, with an estimated population of $128,771,988$, had more than 9 million GSM subscribers, making the country one of the fastest growing GSM markets in the world. At the moment, there are four GSM operators in Nigeria: MTN V-Mobile, Glo Mobile and MTEL. MTN (Adegoke et al., 2008) enjoys the greatest patronage, with over 4 million subscribers. It was predicted that between 2003 and 2006, Nigeria's GSM market would be Africa's fastest-growing mobile market, and this prediction had been fulfilled. The competition is getting fiercer by the day as operators have to compete desperately for the same potential subscribers. Four years after the start of the GSM era in Nigeria, the focus gradually shifted from providing coverage to providing quality service. The euphoria of owning a phone set is gradually giving way to complaints of dropped calls and congestion. The operators are fast realizing that they are in a highly competitive environment where subscribers can make or break them. Dissatisfaction by subscribers gave rise to a high rate of subscriber churn and low revenue for the operator. The performance of the network has a direct impact on the revenues. The NCC is bringing pressure to the operators to step up the quality of service offered Nigerians and had even gone a step further to award contracts to private companies to conduct comparative analyses of the quality of service offered by each of the operators. The NCC is further threatening to sanction any operator that fails to pay attention to quality. It therefore behooves all the operators to ensure that the subscribers enjoy the best of service. This study is aimed at presenting a report of services provided by GSM operators within the township of Epe in Lagos State, Western Nigeria. It tries to evaluate the 
quality of services (Emagbetere et al., 2009) provided by these operators in relation to the standards specified by Nigerian Communication Commission which is the main regulatory body for telecommunication operations in Nigeria.

\section{METHODOLOGY}

In this study, various call quality parameters are being evaluated for three GSM mobile operators, i.e. Operators A, Operator B and Operator C, with existing network infrastructures within Epe town. A total of five parameters were evaluated. These parameters are Call Setup Failure Rate, Call Drop Rate, SDCCH congestion Rate, $\mathrm{TCH}$ availability and Inter and Intra PLMN handover. Various methods have been used by researchers and the industry experts to collect call data within a network PLMN. Call data can be obtained from mere initiating calls from the mobile stations. It can also be obtained from analysis of drive test data. The most commonly used method is by obtaining these parameters from a central monitoring centre called the Operation and Maintenance Centre (OMC), Network Operation Centre (NOC) or the Network Management Centre (NMC). This has since been proved to be the most reliable method of call data collection. This is because the NOC connects directly to the BSC and MSC which are the most sensitive equipments within the GSM infrastructures. Different classes of data are obtained from the NOC including traffic and signaling messages. Reports are then generated from these data via enterprise software applications referred to as Element Management Software EMS. This software provides platforms for reports generation in various file formats with the Microsoft Excel format being the most common. Reports are collected on a daily, weekly, monthly and even yearly basis. This study attempts to investigate (Adebayo et al, 2005) the Quality of Services provided by the three GSM service operators with Epe town of Lagos State, South-West Nigeria by collecting and analyzing call data from the Network Operation Centre. The result of the analysis is then compared with that those specified by the Nigerian Communication Commission NCC.

\section{DATA COLLECTION}

In this study, data collection was obtained from the Network Operation Centre for the three GSM services operators (Operator A, Operator B and Operator C) providing services to Epe town.

The data for a total of twenty three weeks within the periods of January and May, 2009 were obtained showing a detailed research operation. Parameters for analysis here are Call Setup Failure Rate, Call Drop Rate, SDCCH congestion, TCH Availability and Inter + Intra PLMN Handover. The following table shows the data obtained for each of the parameters as above. 
Table 1 Data for Call Setup Failure Rate Call Drop Rate

\begin{tabular}{|c|c|c|c|}
\hline \multirow[b]{2}{*}{ Week } & \multicolumn{3}{|c|}{ Call setup failure rate } \\
\hline & Operator A & Operator B & Operator C \\
\hline Wk1 1/3/2009 & 4.26 & 2.17 & 5.59 \\
\hline Wk2 1/10/2009 & 11.11 & 3.12 & 7.04 \\
\hline Wk3 1/17/2009 & 5.00 & 2.45 & 3.24 \\
\hline Wk4 1/24/2009 & 3.50 & 12.36 & 3.77 \\
\hline Wk5 31/1/2009 & 12.12 & 1.77 & 3.71 \\
\hline Wk6 2/7/2009 & 1.86 & 2.24 & 3.22 \\
\hline Wk7 2/14/2009 & 3.96 & 2.25 & 3.87 \\
\hline Wk8 2/21/2009 & 5.55 & 2.81 & 4.01 \\
\hline Wk9 2/28/2009 & 1.75 & 1.67 & 4.28 \\
\hline Wk10 3/7/2009 & 2.42 & 2.78 & 11.92 \\
\hline Wk11 3/14/2009 & 3.80 & 7.83 & 2.87 \\
\hline Wk12 3/21/2009 & 2.55 & 1.86 & 3.15 \\
\hline Wk13 3/28/2009 & 6.26 & 1.65 & 2.49 \\
\hline Wk14 4/4/2009 & 2.09 & 2.11 & 3.77 \\
\hline Wk15 4/11/2009 & 1.26 & 2.47 & 11.97 \\
\hline Wk16 4/11/2009 & 2.43 & 1.88 & 13.91 \\
\hline Wk17 4/18/2009 & 1.12 & 2.35 & 5.15 \\
\hline Wk18 4/25/2009 & 4.43 & 2.71 & 2.85 \\
\hline Wk19 5/2/2009 & 3.14 & 2.36 & 2.59 \\
\hline Wk20 5/9/2009 & 5.55 & 18.12 & 3.14 \\
\hline Wk21 5/16/2009 & 4.26 & 11.8 & 4.34 \\
\hline Wk22 5/23/2009 & 6.80 & 2.01 & 2.78 \\
\hline Wk23 5/30/2009 & 8.29 & 1.66 & 4.75 \\
\hline
\end{tabular}

\section{Call Setup Success Rate (\%) per Week}

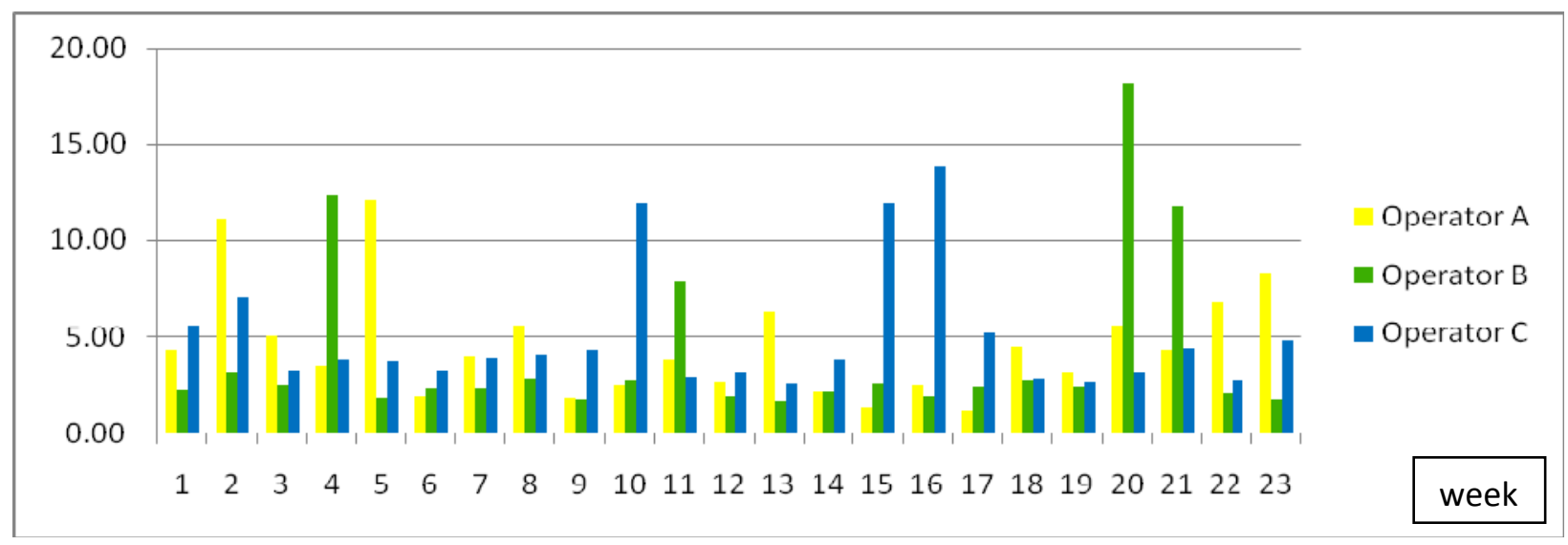


Table 2 Data for Call Drop Rate per week

\begin{tabular}{ll}
\multicolumn{2}{c}{ Week } \\
Wk1 & $1 / 3 / 2009$ \\
Wk2 & $1 / 10 / 2009$ \\
Wk3 & $1 / 17 / 2009$ \\
Wk4 & $1 / 24 / 2009$ \\
Wk5 & $31 / 1 / 2009$ \\
Wk6 & $2 / 7 / 2009$ \\
Wk7 & $2 / 14 / 2009$ \\
Wk8 & $2 / 21 / 2009$ \\
Wk9 & $2 / 28 / 2009$ \\
Wk10 & $3 / 7 / 2009$ \\
Wk11 & $3 / 14 / 2009$ \\
Wk12 & $3 / 21 / 2009$ \\
Wk13 & $3 / 28 / 2009$ \\
Wk14 & $4 / 4 / 2009$ \\
Wk15 & $4 / 11 / 2009$ \\
Wk16 & $4 / 11 / 2009$ \\
Wk17 & $4 / 18 / 2009$ \\
Wk18 & $4 / 25 / 2009$ \\
Wk19 & $5 / 2 / 2009$ \\
Wk20 & $5 / 9 / 2009$ \\
Wk21 & $5 / 16 / 2009$ \\
Wk22 & $5 / 23 / 2009$ \\
Wk23 & $5 / 30 / 2009$
\end{tabular}

Operator A
2.25
10.57
2.77
1.47
3.62
1.76
3.48
4.93
2.83
1.89
2.97
1.80
4.95
2.10
1.08
9.25
1.72
2.66
3.47
4.59
2.56
4.38
3.86

Call Drop Rate

\begin{tabular}{|c|c|}
\hline Operator B & Operator C \\
\hline 2.69 & 2.62 \\
\hline 2.94 & 2.83 \\
\hline 2.56 & 0.54 \\
\hline 11.68 & 1.84 \\
\hline 2.47 & 6.78 \\
\hline 0.61 & 1.11 \\
\hline 1.33 & 1.17 \\
\hline 0.24 & 0.82 \\
\hline 0.33 & 1.04 \\
\hline 1.18 & 3.51 \\
\hline 2.36 & 2.82 \\
\hline 3.29 & 0.69 \\
\hline 4.29 & 3.56 \\
\hline 2.41 & 1.01 \\
\hline 0.39 & 1.70 \\
\hline 5.45 & 7.93 \\
\hline 2.75 & 1.56 \\
\hline 0.62 & 0.87 \\
\hline 4.82 & 1.03 \\
\hline 2.49 & 1.97 \\
\hline 10.47 & 5.76 \\
\hline 0.58 & 11.06 \\
\hline 2.36 & 3.86 \\
\hline
\end{tabular}

\section{Call Drop Rate (\%) against Week}

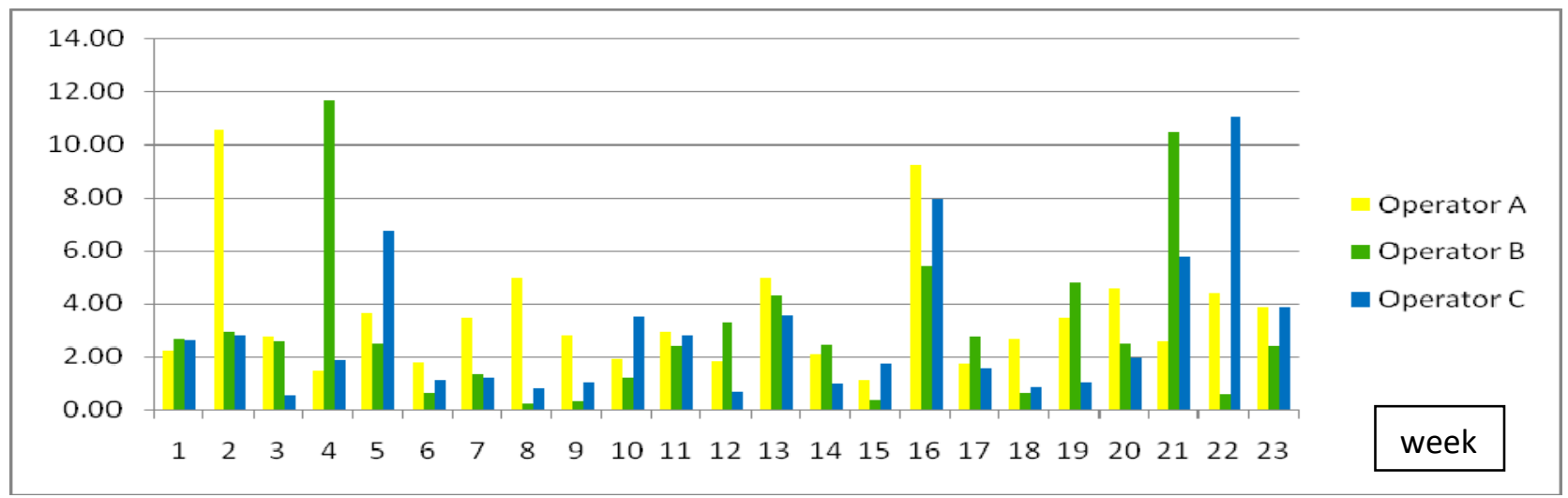


Table 3 Data for SDCCH Congestion

\begin{tabular}{ll}
\multicolumn{2}{c}{ Week } \\
Wk1 & $1 / 3 / 2009$ \\
Wk2 & $1 / 10 / 2009$ \\
Wk3 & $1 / 17 / 2009$ \\
Wk4 & $1 / 24 / 2009$ \\
Wk5 & $31 / 1 / 2009$ \\
Wk6 & $2 / 7 / 2009$ \\
Wk7 & $2 / 14 / 2009$ \\
Wk8 & $2 / 21 / 2009$ \\
$W k 9$ & $2 / 28 / 2009$ \\
$W k 10$ & $3 / 7 / 2009$ \\
$W k 11$ & $3 / 14 / 2009$ \\
$W k 12$ & $3 / 21 / 2009$ \\
$W k 13$ & $3 / 28 / 2009$ \\
$W k 14$ & $4 / 4 / 2009$ \\
$W k 15$ & $4 / 11 / 2009$ \\
$W k 16$ & $4 / 11 / 2009$ \\
$W k 17$ & $4 / 18 / 2009$ \\
$W k 18$ & $4 / 25 / 2009$ \\
$W k 19$ & $5 / 2 / 2009$ \\
$W k 20$ & $5 / 9 / 2009$ \\
$W k 21$ & $5 / 16 / 2009$ \\
$W k 22$ & $5 / 23 / 2009$ \\
$W k 23$ & $5 / 30 / 2009$
\end{tabular}

SDCCH congestion

\section{Operator A}

$$
3.44
$$

15.94

4.37

2.94

9.50

1.81

3.68

5.19

2.16

2.17

4.35

2.34

4.93

1.92

1.92

8.57

8.24

2.32

3.23

4.76

3.77

5.62

6.12

\section{Operator B}

\subsection{1}

5.97

3.34

6.13

6.93

3.15

12.68

4.29

4.00

3.80

5.32

5.06

5.22

3.23

2.94

6.00

2.17

3.99

8.94

3.68

2.34

4.37

1.92

\section{Operator C}

0.00

0.00

0.18

0.00

0.09

0.00

0.00

0.38

0.02

0.00

0.01

0.05

0.00

0.00

0.00

0.00

3.54

0.00

0.78

0.00

0.07

0.00

0.00

\section{SDCCH congestion}

(\%)

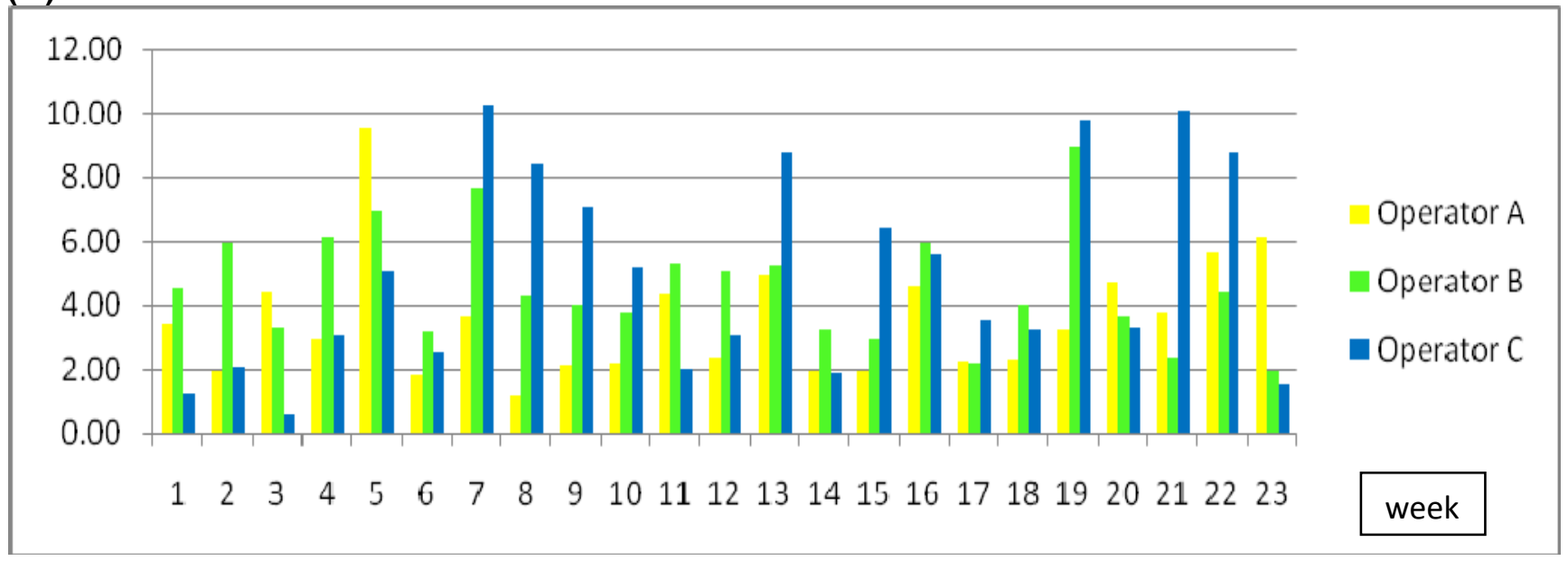


Am. J. Sci. Ind. Res., 2011, 2(3): 409-417

Table 4 TCH Availability

\begin{tabular}{|c|c|}
\hline \multicolumn{2}{|c|}{ Week } \\
\hline Wk1 & $1 / 3 / 2009$ \\
\hline Vk2 & $1 / 10 / 2009$ \\
\hline /k3 & $1 / 17 / 2009$ \\
\hline$/ k 4$ & $1 / 24 / 2009$ \\
\hline Vk5 & $31 / 1 / 2009$ \\
\hline Nk6 & 2/7/2009 \\
\hline Vk7 & $2 / 14 / 2009$ \\
\hline Vk8 & $2 / 21 / 2009$ \\
\hline Vk9 & $2 / 28 / 2009$ \\
\hline Nk10 & $3 / 7 / 2009$ \\
\hline Nk11 & $3 / 14 / 2009$ \\
\hline Wk12 & $3 / 21 / 2009$ \\
\hline Nk13 & $3 / 28 / 2009$ \\
\hline Vk14 & 4/4/2009 \\
\hline Wk15 & 4/11/2009 \\
\hline Wk16 & 4/11/2009 \\
\hline Wk17 & 4/18/2009 \\
\hline Wk18 & $4 / 25 / 2009$ \\
\hline Wk19 & $5 / 2 / 2009$ \\
\hline Wk20 & $5 / 9 / 2009$ \\
\hline Wk21 & $5 / 16 / 2009$ \\
\hline Wk22 & $5 / 23 / 2009$ \\
\hline Wk23 & תמכובו \\
\hline
\end{tabular}

TCH availability

\begin{tabular}{|c|c|c|}
\hline Operator A & Operator B & Operator C \\
\hline 99.99 & 97.83 & 98.31 \\
\hline 99.97 & 99.99 & 98.31 \\
\hline 100.00 & 97.55 & 99.63 \\
\hline 100.00 & 99.99 & 99.80 \\
\hline 100.00 & 98.23 & 99.80 \\
\hline 100.00 & 97.76 & 97.75 \\
\hline 99.98 & 97.75 & 97.72 \\
\hline 99.99 & 97.19 & 97.79 \\
\hline 100.00 & 98.33 & 98.16 \\
\hline 100.00 & 97.22 & 98.16 \\
\hline 99.99 & 98.17 & 98.16 \\
\hline 94.04 & 98.14 & 93.08 \\
\hline 93.98 & 98.35 & 93.08 \\
\hline 94.02 & 99.96 & 93.08 \\
\hline 90.56 & 99.98 & 99.99 \\
\hline 99.98 & 99.92 & 99.99 \\
\hline 99.97 & 99.65 & 99.95 \\
\hline 99.99 & 99.29 & 99.95 \\
\hline 100.00 & 98.64 & 99.95 \\
\hline 99.99 & 79.88 & 99.97 \\
\hline 99.99 & 98.2 & 99.78 \\
\hline 100.00 & 99.99 & 99.99 \\
\hline 100.00 & 98.34 & 99.99 \\
\hline
\end{tabular}

TCH

Availability

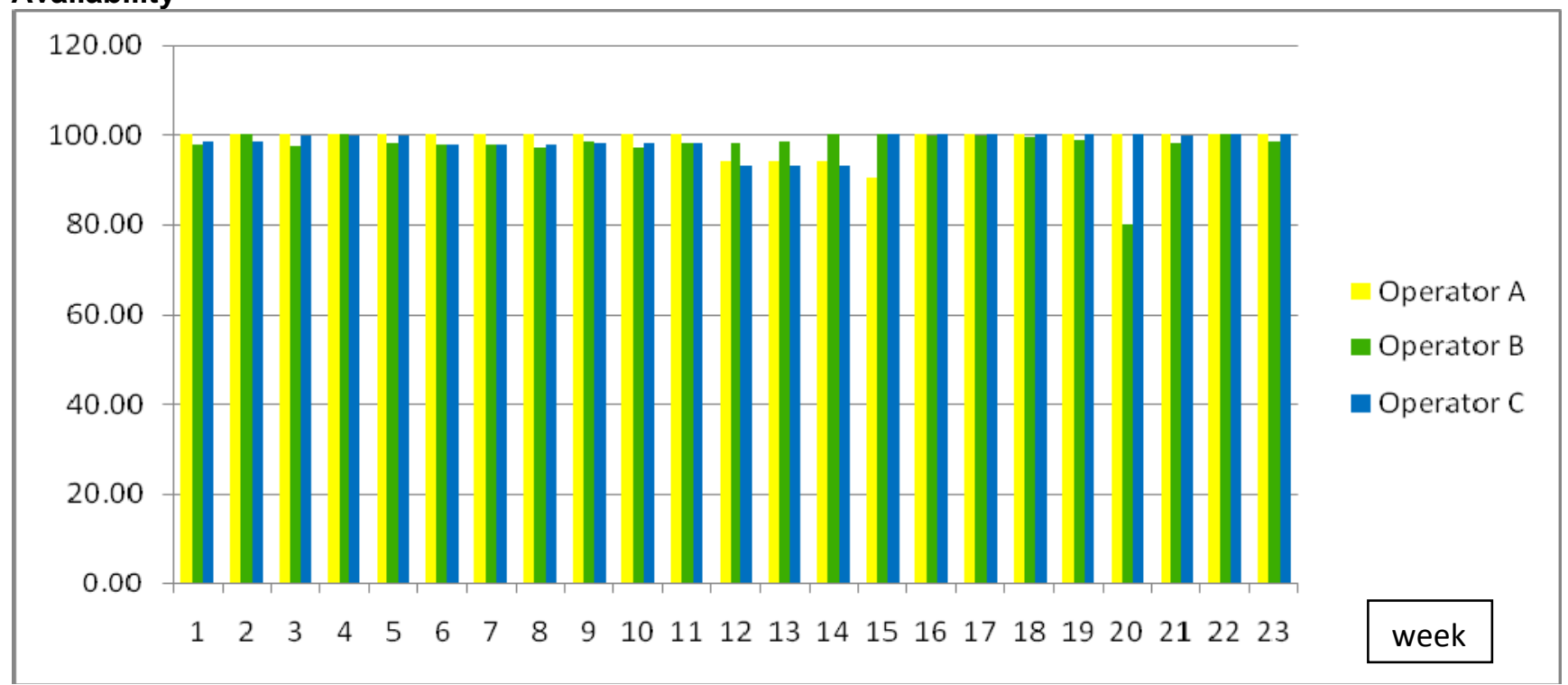


Table 5 Data for Inter + Intra BSC Handover

\begin{tabular}{|c|c|}
\hline & Week \\
\hline Wk1 & $1 / 3 / 2009$ \\
\hline Wk2 & $1 / 10 / 2009$ \\
\hline Wk3 & $1 / 17 / 2009$ \\
\hline Wk4 & $1 / 24 / 2009$ \\
\hline Wk5 & $31 / 1 / 2009$ \\
\hline Wk6 & 2/7/2009 \\
\hline Wk7 & $2 / 14 / 2009$ \\
\hline Wk8 & $2 / 21 / 2009$ \\
\hline Wk9 & $2 / 28 / 2009$ \\
\hline Wk10 & 3/7/2009 \\
\hline Wk11 & $3 / 14 / 2009$ \\
\hline Wk12 & 3/21/2009 \\
\hline Wk13 & $3 / 28 / 2009$ \\
\hline Wk14 & $4 / 4 / 2009$ \\
\hline Wk15 & $4 / 11 / 2009$ \\
\hline Wk16 & $4 / 11 / 2009$ \\
\hline Wk17 & $4 / 18 / 2009$ \\
\hline Wk18 & $4 / 25 / 2009$ \\
\hline Wk19 & $5 / 2 / 2009$ \\
\hline Wk20 & 5/9/2009 \\
\hline Wk21 & 5/16/2009 \\
\hline Wk22 & $5 / 23 / 2009$ \\
\hline Wk23 & $5 / 30 / 2009$ \\
\hline
\end{tabular}

Inter+Intra BSC Handover Failure

\begin{tabular}{|c|c|c|}
\hline Operator A & Operator B & Operator C \\
\hline 0.17 & 0.88 & 0.14 \\
\hline 0.3 & 0.83 & 0.18 \\
\hline 0.38 & 0.98 & 0.07 \\
\hline 0.12 & 0.04 & 0.08 \\
\hline 0.09 & 0.32 & 0.56 \\
\hline 0.18 & 1.33 & 0.48 \\
\hline 0.25 & 0.06 & 0.87 \\
\hline 0.05 & 0.46 & 0.98 \\
\hline 0.19 & 0.07 & 0.67 \\
\hline 0.31 & 0.07 & 0.78 \\
\hline 0.11 & 0.15 & 0.48 \\
\hline 0.12 & 0.94 & 0.67 \\
\hline 0.07 & 1.52 & 0.18 \\
\hline 0.18 & 1.01 & 0.38 \\
\hline 0.25 & 0.2 & 0.35 \\
\hline 0.25 & 0.16 & 0.41 \\
\hline 0.29 & 0.13 & 0.48 \\
\hline 0.51 & 0.62 & 0.68 \\
\hline 0.49 & 0.93 & 0.82 \\
\hline 0.5 & 1.14 & 0.87 \\
\hline 0.14 & 0.05 & 0.22 \\
\hline 0.28 & 0.25 & 0.18 \\
\hline 0.17 & 0.44 & 0.15 \\
\hline
\end{tabular}

Inter + Intra PLMN Handover Failure

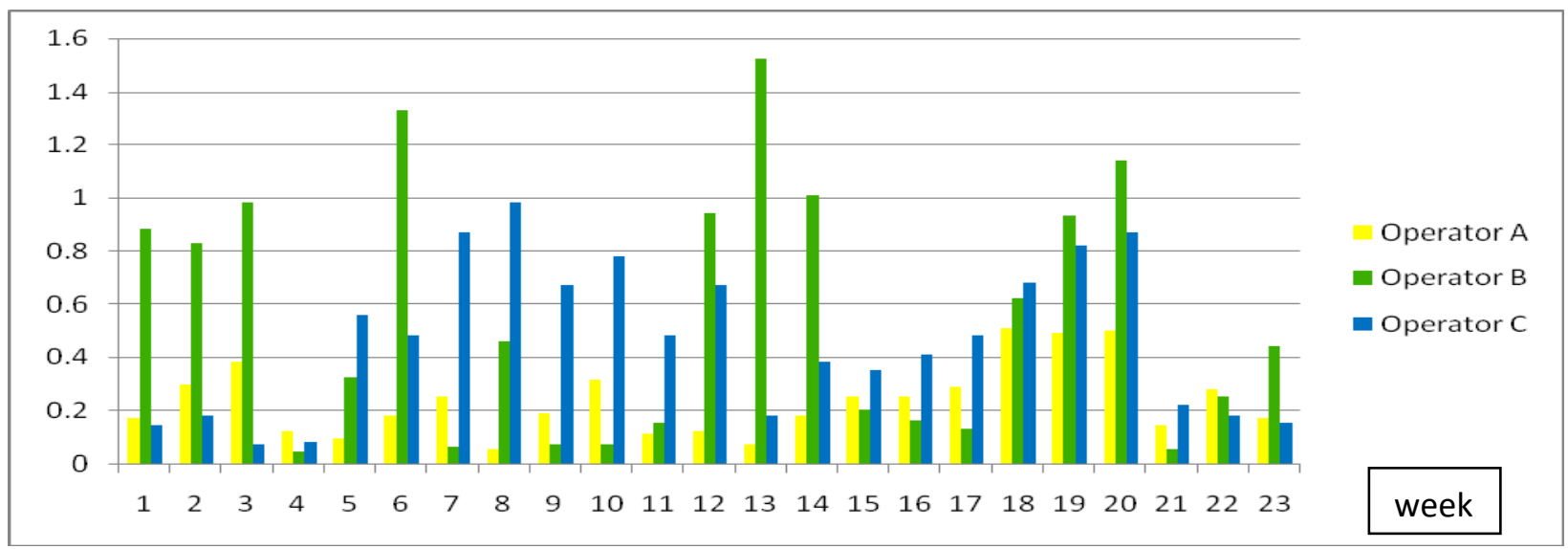




\section{RESULTS INTERPRETATION AND ANALYSIS}

\section{Call Setup Failure Rate}

This refers to the number of the blocked call attempts divided by the total number of call attempts. It is also called the Blocking Probability and expressed in percentage $100 \%$.

Call Setup Failure Rate $=$ Number of Blocked Calls

Number of Call Attempts $\mathrm{X} 100 \%$

Call Setup Failure Rate $=1-$ Call Setup Success Rate

The Nigerian Communication Commission has set a benchmark of $<10 \%$ as an acceptable value which all GSM operators must meet. This result shows that within the weeks 2, 4 and 5 of this research, operators A, B and A respectively did not meet up with the standard. Similarly, results for weeks 10,11 and 15 depicts that operators $B, C$ and $B$ respectively did not meet up with the NCC standards on Call Setup Success.

In the overall, Operator A provided an acceptable Call Setup Failure Rate for twenty out of twenty three weeks of study representing $91.3 \%$ while for Operators B and C, it was twenty out of twenty three representing $87 \%$.

Call Drop Rate (CDR): The Call Drop Rate (Emagbetere et al., 2009) is the number of dropped calls divided by the total number of call attempts.

$$
\begin{aligned}
& \text { CDR }=\frac{\text { Number of Dropped Calls }}{\text { Number of Call Attempts }} \times 100 \% \\
& \text { CDR }=1-\text { Call Completion Ratio } \times 100 \%
\end{aligned}
$$

A dropped call is a call that is prematurely terminated before being released normally by either the caller or called party (i.e., the call is dropped before the exchange of Released Message "RL_M" and Released Complete Message

"RLC_M" in the signaling flow).

This result of this research indicates that Operator had a Call Drop issue only in the second week of this research. Operator $B$ had issues during the first and twenty first week while Operator $C$ experienced its own in the twenty second week.

Operators A and C provided an acceptable Call Drop Rate for about $96 \%$ for the period of this research while that of Operator B also was also acceptable but at $91 \%$.
SDCCH Congestion Ratio: The Stand-Alone Dedicated Control Channel is the channel used for signaling messages. It is concerned with call setup, location update message and Short Message Services (SMS).

$\mathrm{SDCCH}$ congestion has been stipulated by the Nigerian Communication Commission to be less than $10 \%$. The result of this research project shows that all the three operators did not exceed the standard except slightly by Operator $C$ in the $7^{\text {th }}$ week.

TCH Availability: The traffic channel (Adebayo and Edeko, 2005) is that channel used by Mobile Station for communication. $\mathrm{TCH}$ availability is a measure of congestion of the Traffic channel measured at the busy hour.

$\mathrm{TCH}$ Availability =

Busy Hour TCH Traffic (Erlang) - Average TCH Traffic (Erlang) X 100\% Busy Hour TCH Traffic (Erlang)

The results obtained in this research shows that all the three operators meet up the $>90 \%$ requirement stipulated by the Nigerian Communication Commission except for the twenty second week where Operator B had slightly less (79.8\%).

Inter + Inter PLMN Handover Failure Rate: Handover is the process in which a cellular phone is handed from one cell to the next in order to maintain a radio connection with the network.

Inter PLMN handover refers to the handover between two different networks irrespective of the radio access system.

Intra PLMN handover refers to the handover within the same network regardless of the radio access system.

Handover Success Rate is the ratio of the number of successfully completed handovers to the total number of initiated handovers. This ratio can be expresses as a percentage.

Handover Success Rate $=$

Number of successfully completed handovers $x 100 \%$ Number of initiated handovers

Therefore,

Handover Failure Rate $=1-$ Handover Success Rate 
The results obtained indicated that all the three operators do not have issues with the Nigerian Communication Commission specification as regards handover.

\section{CONCLUSION}

The Element Management Software (EMS) provided the platform for report generation in the various formats within the Microsoft Excel package. Data was collected over a period of twenty-three weeks. Parameter analysis were Call Set-up failure rate, Call drop rate, Stand alone dedicated control channel congestion, Traffic channel availability and Handover failure rate. It was observed that these network operators need to improve the quality of service offered to their teeming customers. The call drop rate, call set-up failure and stand-alone dedicated control channel congestion ratio were high for the three network operators as at the time of this study. It is also shown that the traffic channel was readily available during the period of investigation and evaluation and the handover failure rate was accepted judging by the NCC standard. It can be deduce from the investigation that the bad quality of service encountered by these operators is not as a result of the traffic channel which is readily available but from other factors which include the congestion of the SDCCH. It is worthy to mention that for those weeks with high SDCCH congestion, the call drop rate and the call set-up failure rate were high. However, more attention should be focused to improving the quality of service for better performance. Conclusively, the results show that the call results in the area of study is still a far cry from the expectations of customers.

\section{REFERENCES}

Adebayo, T.L and Edeko, F.O, 2005. Investigation on coverage level, accessibility index and propagation pathloss characteristic and working of power received of GSM Signal: A case study of Benin City. Faculty of Engineering, $U$ niversity of Benin PhD Thesis

Adegoke, A.S, Babalola, I.T and Balogun, W.A, 2008. Performance Evaluation of GSM Mobile System in Nigeria" Pacific Journal of Science and Technology. 9(2): $436-441$

Emagbetere, J.O, Aigbodioh, F.A and Edeko, F.O, 2009. Radio network Planning for GSM900 in a Rural Environment. Journal of Mobile Communication 3(1): 8 $-11$

Shoewu, O, Olaniyi, O.M, Olaniyan, O.M and Alausa, D.W.S, 2008. A Review of Generations of Mobile Wireless Networks. Proceedings of Conference at Federal Polytechnic, Ilaro 